\title{
DAMPAK PERUBAHAN TEMPERATUR WARNA LAMPU FLUORESEN PADA PRODUKTIVITAS MENGGAMBAR ARSITEKTUR MANUAL MAHASISWA DI STUDIO GAMBAR
}

\author{
Leonardo \\ (Email: lenard_lee@yahoo.com) \\ Program Studi Desain Interior \\ Fakultas Seni Rupa dan Desain \\ Universitas Kristen Maranatha \\ Jl. Prof. Drg. Surya Sumantri No 65, Bandung, Indonesia
}

\begin{abstract}
ABSTRAK
Semua pencahayaan buatan berdampak pada kualitas aktivitas manusia sehari-hari, secara psikologis temperature warna hangat (kuning) mendukung relaksasi dan sebaliknya warna dingin (putih kebiruan) mendukung kesiagaan untuk bekerja. Tujuan tulisan ini ialah menjabarkan perbedaan pengaruh perubahan temperatur warna pada produktivitas menggambar manual mahasiswa di studio gambar dalam jangka pendek. Metode semi eksperimental dengan tes gambar detil interior pada total 26 mahasiswa interior semester enam dilakukan di dua studio berkapasitas sama selama dua hari dengan jam yang sama, masing-masing berdurasi lima jam tanpa jeda. Kedua studio diberikan pencahayaan buatan dengan temperatur warna berbeda. Kelengkapan elemen tergambar dan mutu penggambaran ditelaah untuk menilai kondisi pencahayaan. Temuan menunjukkan dampak perubahan warna temperatur dari $2700 \mathrm{~K}$ ke $6500 \mathrm{~K}$ kentara dalam jangka pendek pada produktivitas dan tidak kentara dari campuran $4000 \mathrm{~K}$ dan $6500 \mathrm{~K}$ ke $4000 \mathrm{~K}$. Manfaat riset ini mengusulkan optimalisasi tata cahaya studio gambar agar mahasiswa dapat bekerja dalam waktu panjang dengan mengurangi beban kerja mata sehingga luaran menggambar dan terlebih dampaknya pada hasil mendesain menjadi positif.
\end{abstract}

Kata kunci: menggambar manual; mutu penggambaran; pencahayaan buatan; produktivitas; temperatur warna

\begin{abstract}
All artificial lightings have effects on human daily activities. Psychologically, warm colour temperature gives relaxation feelings and cool colour temperature promotes alertness to most activities. This present study aims to describe the alteration of colour temperature from artificial lighting on manual students drawing productivity in drawing studio within a short period. A semi-experimental approach is conducted in two studios on a par for two days, involving 26 students of sixth semester to draw a set of interior details to finish in five hours each session on the same time. Each studio is installed with fluorescent tube lamps with different colour temperature for each session. The drawing elements comprehensiveness and the drawing quality are examined to assess lighting condition in the studios. Findings show that the alteration of colour temperature from $2700 \mathrm{~K}$ to $6500 \mathrm{~K}$ is significantly positive to productivity while mix of $4000 \mathrm{~K}$ and $6500 \mathrm{~K}$ to $4000 \mathrm{~K}$ is not significant. The benefit of this study leads to reference to lighting design criteria for drawing studio in design institute to enable students to work in a prolonged time without eye overburden. Hence the design brings positive output.
\end{abstract}

Keywords: artificial lighting; color temperature; drawing qualification; manual drawing; productivity 


\section{PENDAHULUAN}

Spektrum cahaya dengan gelombang pendek yang tampak dalam temperatur warna tinggi/sejuk telah dikonfirmasikan mendukung kondisi awas saat bekerja sehingga meningkatkan konsentrasi dan akhirnya mendukung kinerja belajar (Deguchi T et al dalam Mills et al, 2007). Di sisi lain, temuan bahwa cahaya $7500 \mathrm{~K}$ meningkatkan aktivitas vasomotor sehingga berdampak pada kondisi awas (Morita dan Tokura, 1996).

Berbagai penelitian yang dilakukan terkait dampak signifikan temperatur warna pada konsentrasi belajar (Sleegers et al, 2012 ; Shamsul et al, 2013) dan kinerja belajar (Samani, 2011), juga kinerja pekerja kantor (Mills et al, 2007) secara psikologis menjadi landasan penelitian produktivitas menggambar arsitektur manual mahasiswa di studio gambar. Penelitian ini memfokuskan pada telaah kinerja menggambar manual mahasiswa sebagai dampak dari perubahan temperatur cahaya, yang kasusnya dilakukan di dalam studio gambar di lingkungan belajar suatu perguruan tinggi desain interior. Kasus studi ini masih sedikit diangkat sehingga sangat terbuka luas, sekaligus menjadi tantangan bagi bahan penelitian mengingat bahwa sudah banyak penelitian di bidang pencahayaan yang telah dilakukan seperti misalnya, untuk menelaah kinerja murid sekolah dasar (Heschong et al, 2002), ruang belajar yang efektif bagi mahasiswa di perguruan tinggi (Stone, 2001) atau di perkantoran (Tonello, 2004). Penelitian ini juga memperkaya temuan terkait isu produktivitas yang juga menelaah kinerja menggambar (Padmanaba, 2006) namun dari sisi tingkat pencahayaan. Isu ini diangkat mengingat bahwa kegiatan belajar secara khusus merupakan bagian dari aktivitas bekerja yang memiliki keunikannya tersendiri untuk mencapai keterampilan tertentu. Di samping itu, keberadaan studio gambar merupakan fasilitas penting bagi institusi pendidikan tinggi desain yang tentunya disediakan untuk dapat menunjang kegiatan belajar mendesain agar optimal.

Penelitian cross-sectional adalah jenis penelitian yang mengamati fenomena pada satu waktu tertentu secara eksploratif, deskriptif, atau eksplanatif (Nurdini, 2006). Oleh sebab itu, penelitian ini bertujuan untuk mendeskripsikan perbedaan pengaruh perubahan temperatur warna pada produktivitas menggambar manual mahasiswa di studio gambar dalam jangka pendek. Dalam kasus studi yang dipilih, keterampilan menggambar teknik yang merupakan bagian dari kurikulum pembelajaran - selalu diasah dengan cara mahasiswa harus menyelesaikan sejumlah gambar dalam durasi waktu tertentu sebagai bentuk dokumentasi akhir desain interior. 


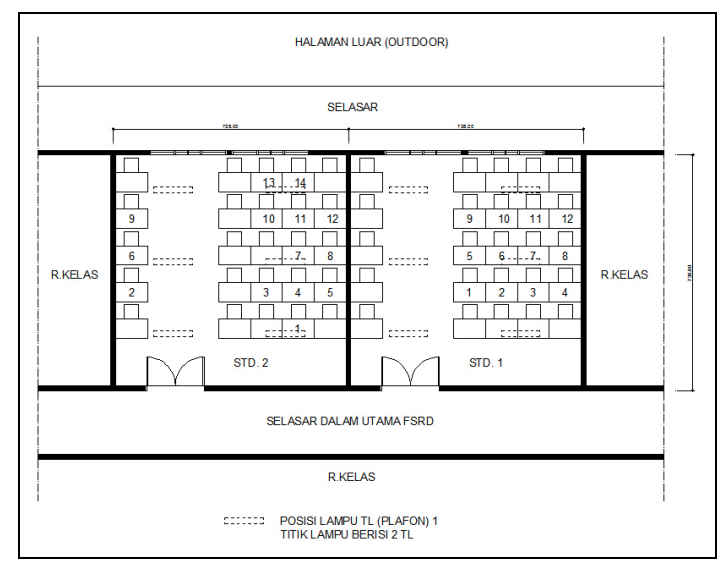

Gambar 1. Dokumentasi pribadi data geometrik studio pertama dan kedua - kondisi faktual Sumber: Data penulis, 2015

Dengan demikian penelitian ini mampu menambahkan hasil temuan dalam lingkup bidang pencahayaan dan tata cahaya dalam institusi pendidikan tinggi desain berupa optimalisasi tata cahaya studio gambar melalui konfigurasi temperatur warna pencahayaan agar mahasiswa dapat bekerja dalam waktu panjang dengan mengurangi beban kerja mata sehingga luaran menggambar dan terlebih dampaknya pada hasil mendesain menjadi positif.

\section{Produktivitas}

Produktivitas secara umum diartikan dengan hubungan dengan perbandingan terbalik antara luaran suatu pekerjaan terhadap sumber daya yang dikeluarkan untuk menghasilkan luaran tersebut. Produktivitas dinilai memberikan hasil positif apabila jumlah luaran meningkat walaupun jumlah masukan awal tetap atau bahkan berkurang, juga apabila jumlah luaran yang berlipat ganda dengan menambah masukan.

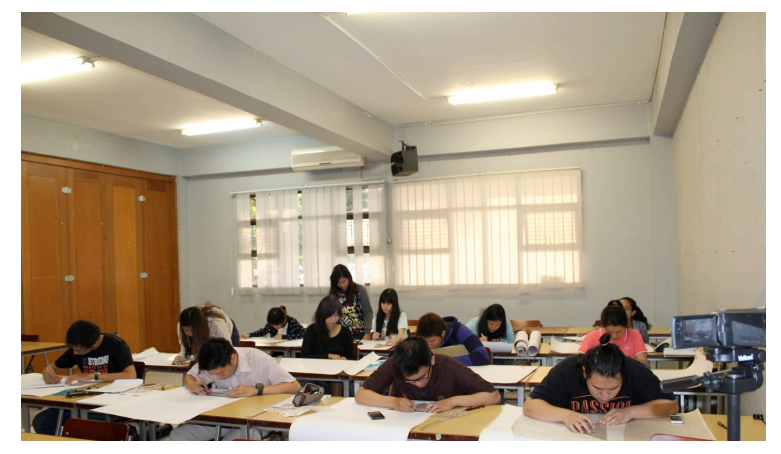

Gambar 2. Foto situasi studio gambar 1 hari pertama - pasangan murni $2700 \mathrm{~K}$ Sumber : Data penulis, 2015 


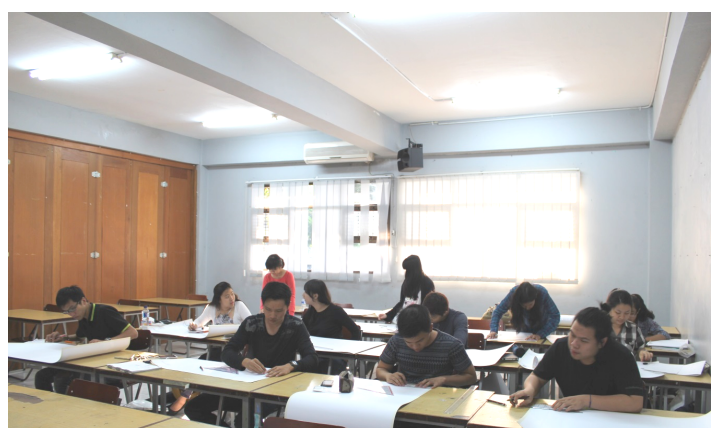

Gambar 3. Foto situasi studio gambar 1 hari kedua - pasangan murni $6500 \mathrm{~K}$ Sumber : Data penulis, 2015

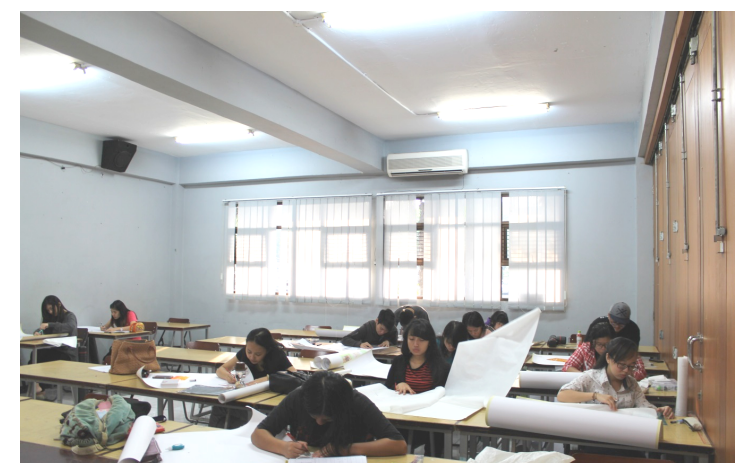

Gambar 4. Foto situasi studio gambar 2 hari pertama - pasangan campuran $4000 \mathrm{~K}+6500 \mathrm{~K}$ Sumber : Data penulis, 2015

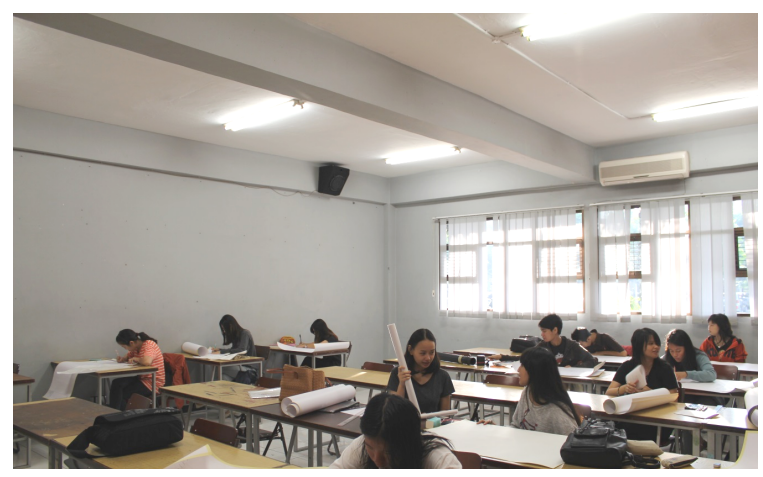

Gambar 5. Foto situasi studio gambar 2 hari kedua - pasangan murni 4000K Sumber : Data penulis, 2015

Produktivitas mencakup kualitas fisik dan nonfisik manusia, teknologi yang digunakan, dan suasana lingkungan kerja (Grandjean, 1998 dan Manuaba, 1992 dalam Padmanaba, 2006). Kualitas nonfisik diartikan dengan semangat diri untuk meningkatkan mutu kerja sehingga proses kerja semakin baik di samping luaran yang kasat mata untuk mengukur produktivitas (Sedarmayanti, 1996 dalam Padmanaba, 2006). Vischer (2008) mengelompokkan tiga tingkat produktivitas, yaitu perorangan, kelompok orang, dan organisasi. Pada tingkat perorangan, menurutnya, aspek lingkungan pencahayaan dapat mempengaruhi kecepatan dan ketepatan seseorang dalam menyelesaikan pekerjaannya. 
Penelitian ini memberikan batasan pengukuran produktivitas dengan berfokus pada produk gambar teknik yang dibuat manual oleh mahasiswa desain interior sebagai bentuk dokumentasi akhir desain, Produktivitas menggambar manual di sini dinilai melalui jumlah gambar yang harus dihasilkan dalam waktu tertentu dengan melihat jumlah kelengkapan elemen tergambar dari suatu jenis gambar menurut standar baku umum gambar teknik, yaitu atribut-atribut gambar yang menyertainya. Mutu penggambaran sebagai bagian penilaian produktivitas dilihat melalui mutu menggambar tipe ketebalan dan karakter garis, dan tingkat kesesuaian penerapan standar baku atribut gambar pada produk yang dihasilkan.

Produktivitas menggambar diartikan positif jika terdapat penambahan jumlah gambar yang dihasilkan dalam durasi waktu tertentu, meningkatnya jumlah kelengkapan elemen tergambar dalam satu jenis gambar (misalnya penerapan atribut baku pada denah, atau potongan) dan meningkatnya mutu penggambaran. Sebaliknya, kondisi negatif berarti waktu yang diperlukan lebih lama untuk menyelesaikan suatu gambar, berkurangnya jumlah total gambar yang dapat diselesaikan dalam waktu yang telah ditentukan, berkurangnya kelengkapan elemen tergambar, dan menurunnya mutu penggambaran.

\section{METODE PENELITIAN}

Penelitian kuantitatif yang bercirikan cross-sectional ini menerapkan pendekatan semi eksperimental untuk melihat pengaruh perubahan temperatur warna cahaya pada tingkat produktivitas menggambar manual mahasiswa di studio. Produktivitas yang merepresentasikan kinerja menggambar manual akan dilihat dengan cara melakukan tes gambar detil interior pada sejumlah mahasiswa. Tes berdurasi masing-masing lima jam dilaksanakan dua kali di waktu yang sama pada hari yang berbeda di dua studio gambar yang berkapasitas sama (panjang 7,5 meter; lebar 7,5 meter; tinggi plafon 3 meter), dengan kondisi desain interior dan tata letak meja kursi yang setara, dan juga memiliki konfigurasi posisi dan jumlah armatur yang sama, masing-masing terdiri dari enam armatur berisikan sepasang lampu fluoresen TL Phillips 36W. Pencahayaan studio murni menggunakan pencahayaan buatan yang bersumber dari lampu fluoresen TL tadi (tidak ada sumber pencahayaan lain dari luar) untuk mempertahankan kemurnian temperatur warna yang dipancarkan untuk diteliti pengaruhnya. Masing-masing studio diberikan perlakuan pencahayaan dengan temperatur warna berlainan. Pada tes hari pertama studio 1 
menggunakan pasangan murni $2700 \mathrm{~K}$ dan studio 2 pasangan campuran $4000 \mathrm{~K}$ dan $6500 \mathrm{~K}$, selanjutnya pada tes hari kedua, studio 1 menggunakan pasangan murni $6500 \mathrm{~K}$ dan studio 2 pasangan murni 4000K. Produktivitas menggambar dari masing-masing studio kemudian ditelaah dengan cara membandingkan tingkat kelengkapan elemen tergambar dan mutu penggambaran menurut pembedaan perlakuan temperatur warna pencahayaan.

\section{Pengukuran Fisik Pencahayaan}

\section{dan Geometrik Studio}

Jenis data yang dikumpulkan dari ruangan studio yang digunakan adalah pengukuran kondisi fisik pencahayaan dan geometrik studio. Tingkat pencahayaan pada ketinggian meja kerja tiap peserta diukur dengan luxmeter, sedangkan temperatur warna diperoleh dari data produk pabrik. Kondisi lingkungan visual, geometrik, dan pencahayaan buatan di dalam studio didokumentasikan dengan pemotretan tanpa flash untuk mempertahankan tampilan rekaman kondisi visual faktual, dan juga mencatat ukuran ruangan, posisi dan konfigurasi titik lampu.

Mahasiswa yang dipilih sebagai responden untuk ikut serta dalam tes gambar adalah mahasiswa aktif semester enam sebanyak 26 orang. Jumlah tersebut diperoleh dari responden yang bersedia berpartisipasi dan juga mengingat kapasitas tiap studio gambar yang relatif kecil hanya cukup untuk menampung belasan mahasiswa. Mereka semua yang terpilih adalah mahasiswa yang sedang mengikuti studio perancangan interior di tingkat yang sama karena mempertimbangkan pengetahuan dan keterampilan menggambar yang dimiliki harus setara untuk mengikuti tes. Dua set gambar detil interior bertipe ortografik masing-masing berskala $1: 20$

dan 1:10 yang terdiri atas denah (1), potongan (2), detil konstruksi (2), dan perspektif furnitur tanpa skala (1) diberikan untuk diselesaikan oleh responden secara manual dengan drawing pen (ketebalan $0.8 \mathrm{~mm}, 0.4 \mathrm{~mm}$, dan $0.1 \mathrm{~mm}$ ) dan penggaris dalam waktu lima jam. Responden bebas menentukan urutan gambar yang dikerjakan pada tiap tes namun tetap mengerjakan jumlah gambar yang sama di tiap tes. Selain itu, mereka diminta duduk pada posisi yang sama selama tes dilaksanakan karena selanjutnya setelah tiap tes selesai akan diminta memberikan masukan berupa evaluasi kondisi dan preferensi pencahayaan studio gambar melalui kuesioner sebagai uji silang atas hasil tes gambar. 


\section{Analisis Univariat}

Analisis univariat dipilih untuk menjelaskan hubungan sebab-akibat yang digunakan pada tingkat pencahayaan (variabel terikat) untuk menelaah dinamikanya sebagai akibat dari perubahan temperatur warna (variabel bebas) oleh penggantian lampu. Begitu pula halnya dengan hasil tes gambar (variabel terikat) setelah diolah ke dalam bentuk nilai. Nilai tersebut kemudian dikelompokkan atas dua kategori yaitu kelengkapan elemen tergambar (KET) yang menjelaskan jumlah kelengkapan komponen gambar, dan mutu penggambaran (MP) yang menjelaskan mutu menggaris sesuai standar baku umum yang berlaku untuk gambar teknik. Baik KET maupun MP diberi tiga skala nilai dengan rentang antar nilai 1, mulai dari yang terendah (0) hingga tertinggi (2). Nilai KET diartikan berturutan sebagai berikut $0=$ tidak tergambar ; $1=$ tidak lengkap ; 2 = lengkap tergambar, sedangkan pada nilai MP, $0=$ tidak tergambar, 1 = tidak sempurna, dan $2=$ sempurna tergambar. Selanjutnya analisis korelasi digunakan untuk menjelaskan pengaruh perubahan temperatur warna pada produktivitas menggambar.

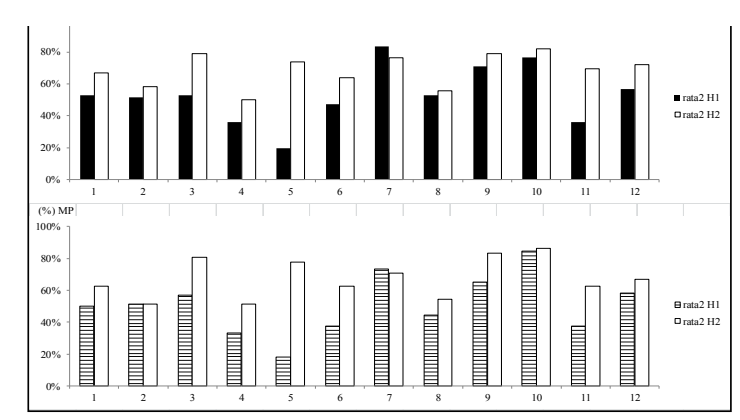

Grafik 1. Hasil olah nilai KET dan MP rata-rata dari responden di studio 1 (Sumber : Data penulis, 2015)

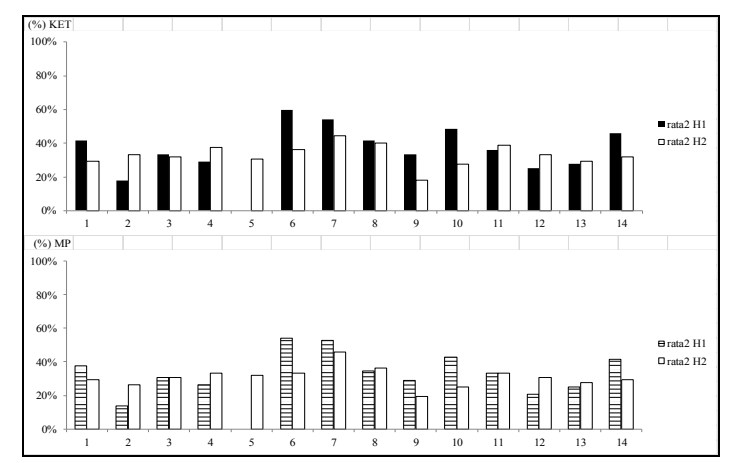

Grafik 2. Hasil olah nilai KET dan MP rata-rata dari responden di studio 2 (Sumber : Data penulis, 2015) 


\section{PEMBAHASAN}

\section{KET dan MP}

Kinerja menggambar yang ditunjukkan oleh responden di studio pertama menunjukkan peningkatan signifikan baik pada nilai KET rata-rata sebesar 15,85\% maupun nilai MP ratarata sebesar $16,55 \%$ saat lampu diganti dari pasangan murni $2700 \mathrm{~K}$ menjadi pasangan murni $6500 \mathrm{~K}$. Perubahan temperatur warna tersebut berpengaruh pula pada naiknya tingkat pencahayaan rata-rata sebesar 63 lux (21\%). Di studio kedua penggantian lampu dari pasangan campur (4000K dan 6500K) menjadi pasangan murni 4000K justru memperlihatkan penurunan baik pada nilai KET rata-rata sebesar $-3,27 \%$ maupun nilai MP rata-rata sebesar $-2,98 \%$, padahal kondisi ini menyebabkan naiknya tingkat pencahayaan rata-rata sebesar 17,07 lux (4,97\%). Jika kinerja menggambar dibandingkan antara responden studio pertama dan kedua, maka terlihat adanya perbedaan nilai KET rata-rata di studio pertama lebih tinggi daripada nilai KET rata-rata di studio kedua, hal yang sama pula dengan nilai MP rata-rata di studio pertama lebih tinggi daripada nilai MP rata-rata di studio kedua. Kondisi tersebut terjadi baik di tes hari pertama maupun tes hari kedua yang samasama diwarnai oleh naiknya tingkat pencahayaan walaupun ada perbedaan, peningkatan lebih besar terjadi di studio pertama daripada peningkatan di studio kedua.

\section{Produktivitas Menggambar Manual}

Menurut dinamika perolehan nilai KET dan MP di tiap studio terlihat bahwa perubahan temperatur warna memiliki konsekuensinya masing-masing secara berbeda. Perubahan dari pasangan murni $2700 \mathrm{~K}$ (hangat) menjadi pasangan murni $6500 \mathrm{~K}$ (sejuk) memberikan kontribusi pada peningkatan kinerja menggambar secara signifikan di studio pertama. Sedangkan perubahan dari pasangan campur (6500K dan $4000 \mathrm{~K})$ menjadi pasangan murni 4000K di studio kedua malah memberikan kontribusi pada penurunan kinerja menggambar walaupun tidak signifikan. Berdasarkan hasil analisis di atas maka besaran produktivitas menggambar manual dapat digambarkan sebagai berikut:
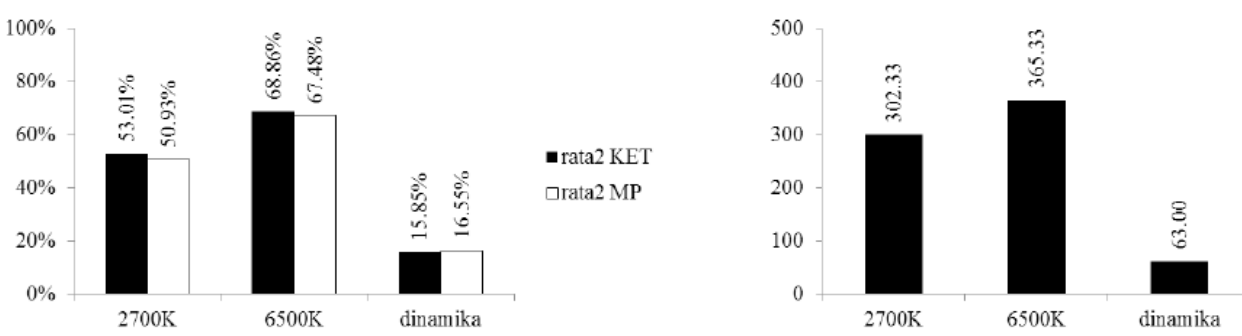

Grafik 3. Produktivitas menggambar manual (\%) menurut temperatur warna di studio 1 (Sumber : Data penulis, 2015) 


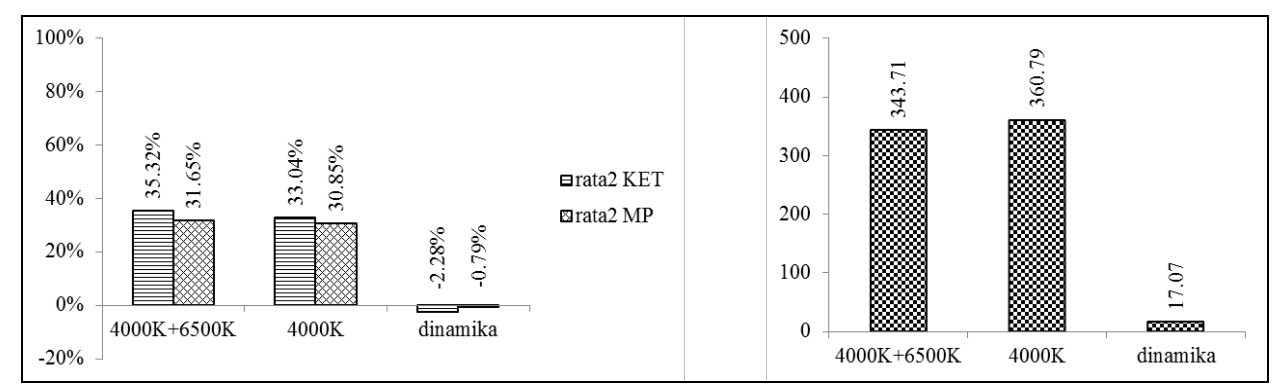

Grafik 4. Produktivitas menggambar manual (\%) menurut temperatur warna di studio 2 (Sumber : Data penulis, 2015)

1. Pada tes hari pertama produktivitas di studio pertama menunjukkan capaian nilai KET rata-rata sebesar 53,01\%, nilai MP rata-rata sebesar 50,93\% dan di studio kedua capaian nilai KET rata-rata sebesar 35,32\%, nilai MP rata-rata sebesar 31,65\% dengan kondisi tingkat pencahayaan rata-rata sebesar 302,33 lux (studio pertama), dan 343,71 lux (studio kedua)

2. Pada tes hari kedua produktivitas di studio pertama menunjukkan capaian nilai KET ratarata sebesar 68,86\%, nilai MP rata-rata sebesar 67,48\% dan di studio kedua capaian nilai KET rata-rata sebesar 33,04\%, nilai MP rata-rata sebesar 30,85\% dengan kondisi tingkat pencahayaan rata-rata sebesar 363,33 lux (studio pertama), dan 360,79 lux (studio kedua).

3. Dinamika produktivitas (hari pertama ke hari kedua) studio pertama menunjukkan peningkatan nilai KET rata-rata sebesar 15,85\%, peningkatan nilai MP rata-rata sebesar $16,55 \%$, dan di studio kedua penurunan nilai KET rata-rata sebesar $-2,28 \%$, dan penurunan nilai MP rata-rata sebesar $-0,79 \%$.

\section{PENUTUP}

Temuan dari penelitian ini adalah bahwa dalam jangka waktu relatif pendek yaitu selama tes dilaksanakan ternyata perubahan temperatur warna dari 2700K (hangat/kuning) menjadi 6500K (sejuk/putih kebiruan) dapat segera berdampak pada peningkatan kinerja menggambar, namun perubahan temperatur warna yang relatif dekat, 4000K dan 6500K (campuran) menjadi 4000K tidak memberikan kontribusi positif. Terlihat pula dari dinamika tingkat pencahayaan yang merupakan dampak perubahan temperatur cahaya dari kedua studio ternyata walaupun keduanya menunjukkan peningkatan (dari tes hari ke-1 menuju tes hari ke-2) tetapi hal tersebut nampaknya tidak sejalan dengan perolehan nilai rata-rata KET dan MP yang ditunjukkan. 
Selain itu, temuan ini pun hendak mengkonfirmasikan temuan sebelumnya bahwa tingkat pencahayaan buatan yang rendah dapat melemahkan baik penglihatan maupun aspek nonvisual lingkungan pencahayaan (Hoffman et al, 2007), juga mendukung kesimpulan Berman (2006) bahwa perubahan temperatur warna dari rendah ke tinggi mampu mendukung kualitas lingkungan visual. Penulis menarik kesimpulan bahwa produktivitas menggambar masih tetap dapat meningkat walaupun dalam jangka waktu pendek, namun dari perbandingan produktivitas kedua studio ternyata terlihat adanya inkonsistensi. Hal itu dipengaruhi faktor manusia, yaitu keterampilan, prioritas gambar yang dikerjakan, dan juga tekanan psikologis dari target gambar yang harus diselesaikan.

Temuan ini baru dapat mengungkapkan dan mengkonfirmasikan temuan sebelumnya bahwa perubahan temperatur warna dari hangat ke sejuk mampu menaikkan kinerja menggambar. Dalam jangka waktu pendek perubahan tersebut ternyata sudah dapat dirasakan, dengan demikian dapat diusulkan untuk mengadakan penelitian berulang di masa depan untuk melihat pola yang berlaku dalam jangka panjang pada perubahan temperatur warna dalam waktu-waktu tertentu agar produktivitas menggambar dapat dipelihara.

Keterbatasan penelitian ini ada pada kesulitan pengukuran secara presisi tingkat keselesaian dan mutu gambar untuk menggambarkan produktivitas dan kinerja menggambar akibat dari keragaman kemampuan apresiasi responden yang ditunjukkan saat menggambar detil interior. Kemungkinan munculnya Hawthorne effect dalam penelitian ini pun muncul yang disebabkan oleh pengawasan saat tes dan target yang harus diselesaikan sehingga hal ini dapat memengaruhi kinerja menggambar.

\section{DAFTAR PUSTAKA}

Berman, SM et al. (2006). A Comparison of Traditional and High Colour Temperature Lighting on The Near Acuity of Elementary School Children. Lighting Research Technology 38,1, p.41-52 2006.

Heschong, Lisa et al. (2002). Daylighting Impacts on Human Performance in School. Journal of The Illuminating Engineering Society 2002.

Hoffman, Georg et al. (2008). Effects of Variable Lighting Intensities and Colour Temperatures on Sulphatoxymelatonin and Subjective Mood in an Experimental Office Workplace. Applied Ergonomics 39 (2008) 719 - 728. 
Mills, Peter R et al. (2007). The Effect of High Correlated Colour Temperature Office Lighting on Employee Wellbeing and Work Performance. Journal of Circadian Rhythms 2007, 5:2.

Morita, Takeshi dan Tokura, Hiromi. (1996). Effects of Lights of Different Color Temperature on The Nocturnal Changes in Core Temperature and Melatonin in Humans. Applied Human Science. Journal of Phsycological Anthropology p.243-246 1996.

Nurdini, Allis. (2006). "Cross-Sectional vs Longitudinal" : Pilihan Rancangan Waktu dalam Penelitian Perumahan Permukiman. Jurnal Dimensi Teknik Arsitektur Vol.34 no.1 Juli $2006: 52-58$.

Padmanaba, Cok Gd Rai. (2006). Pengaruh Penerangan dalam Ruang Terhadap Produktivitas Kerja Mahasiswa Desain Interior. Dimensi Interior, vol.2 no.2 hal.57-63 2006.

Samani, Sanaz A. (2011). The Influence of Light on Students' Learning Performance in Learning Environments : A Knowledge Internalization Perspective. World Academy of Science, Engineeering and Technology 572011.

Shamsul B.M.T, C.C.Sia, Y.G Ng, Karmegan, K. (2013). Effects of Lights' Colour Temperatures on Visual Comfort Level, Task Performances, and Alertness among Students. American Journal of Public Health Research, vol.1 no.7 p.159-165, 2014.

Sleegers, PJC et al. (2012). Lighting Affects Students' Concentration Positively : Findings from Three Dutch Studies. Ligthing Research Technology. 2013 ; 45 : 159-175.

Stone, Nancy J. (2001). Designing Effective Study Environments. Journal of Environmental Psychology. 21, p.179-190 2001.

Tonello, Graciela. (2004). "How is Workers' Mood Affected by Worksplace Lighting ?". Journal of Lighting and Visual Environment vol.28.n0.3 p.139-147. 2004

Vischer, Jacqueline C. (2008). Towards an Environmental Psychology of Workspace : How People are Affected by Environments for Work. Architectural Science Review vol.51.2 p.97-1082008. 